\title{
El trabajo interdisciplinario en la investigación histórica de la educación. \\ Imágenes y sentidos: la fotografía histórica, una aproximación a la semiótica de la imagen \\ Belinda Arteaga Castillo \\ Universidad Pedagógica Nacional, Unidad Ajusco
}

\section{Reflexiones iniciales}

Algunos objetos de la investigación histórica parecen ser campos propicios para el diálogo entre distintas voces y la convergencia de diversas miradas teóricas y/o metodológicas, pues las complejidades de su aprehensión vuelven imperativa la apertura hacia múltiples perspectivas que se entrecruzan y complementan para develar, comprender y otorgar sentido a incógnitas que se resisten a ser esclarecidas a partir de un solo campo disciplinario.

De esta manera, las cuestiones que tienen que ver con la historia de las mujeres y las relaciones de género; las regiones, sus espacios y fronteras materiales o simbólicas; la educación, sus instituciones y actores, se encuentran situadas, a no dudarlo, en ese espacio polisémico, resistente a las interpretaciones monocordes, a las respuestas únicas y universales. Tanto más si estos relatos se enriquecen con las narrativas icónicas que, a su manera, se constituyen en procesos de significación susceptibles de ser aprehendidos a través de una "aventura semiológica" que no ofrece nunca un puerto seguro de llegada para quien la emprende pero que, como el mítico canto de las sirenas, suele seducir a los viajeros.

Este ejercicio exige un trabajo riguroso de desciframiento no exento del riesgo a partir del cual (a través de fotografías, dibujos, grabados y, en general, de toda"representación planaria") nos enfrentamos al mundo concebido, imaginado, puesto en escena por actores y sujetos que, desde sus propios referentes histórico-culturales -que son siempre horizontes de interpretación- han plasmado historias dignas de ser contadas.

Obvio es decir que, para el análisis, las imágenes no pueden ser vistas como simples "ilustraciones" de un libro o de un momento histórico, sino como anclajes significativos que en interrelación con lo textual permiten la construcción de sentido y coadyuvan a una lectura hipotética (siempre frágil) de lo representado en tanto "materialidad y, a la vez, significación potencial".' Vistas de este modo, las imágenes tampoco pueden ser comprendidas como signos abstractos y estereotipados, alejados del significante, ni su "lectura" concebida como la simple traducción de iconos a palabras.

Las imágenes constituyen sistemas semiológicos en permanente transformación, y se vinculan a diversos horizontes significativos relativamente independientes (cultu- 
rales, lingüísticos, históricos, sociales, etcétera) a partir de los cuales las metáforas, las analogías y las discrepancias se develan y adquieren sentido.

El signo, como afirma Saussure, no está puesto en el mundo como un argumento para ser comunicado, sino que requiere de ser construido. Desde esta perspectiva, "se concibe a los significantes más bien como espera de significados posibles y se vuelve a considerar la noción de signos individualizados (versus la tendencia fragmentadora dominante en la primera semiología) con el fin de establecer series de signos que se agrupen según un procedimiento que podríamos describir como una vectorización. La vectorización es un medio a la vez metodológico mnemotécnico y dramático para vincular redes de signos. Consiste en asociar y conectar signos que se toman como redes en cuyo interior cada uno tiene sentido únicamente por la dinámica que lo vincula a los demás".

Sin embargo, esta globalización no está exenta de riesgos, puesto que el análisis emprende una búsqueda de una especie de clave secreta de la escenificación, de su forma centrada y concentrada, lo que excluye las prácticas escénicas que se fundan en el descentramiento, lo arbitrario o el azar. Para evitar este cierre.... "hay que poner el énfasis en un recorrido de sentido que interrelaciona a los signos y cuya permanente tensión conlleva un comportamiento dinámico... La descripción... siempre oscila entre la exigencia totalizadora de síntesis y una individualización empírica, entre el orden y el caos, entre la abstracción y la materialidad".2

Por lo tanto, una lectura interesada de fotografías históricas, lo mismo que de imágenes como los cromos de un libro de texto o los grabados empleados como material didáctico en las aulas o las fotografías históricas, implica el reconocimiento de que estos documentos constituyen huellas tangibles del pasado/presente de la historia en el más extenso sentido del término (como proceso pretérito y contemporáneo, como narración, como registro autobiográfico), pero que "por sí mismos no dicen nada. Hay que hacer que signifiquen y para ello hay que ponerles en una especie de relación de actualización con otros elementos relativos, como los textos".3

Es tarea del analista resaltar su dimensión documental y dar cuenta de la lógica de sentido que se condensa en una mirada, una actitud, un indicio, así como en el argumento contenido en el plano global de la imagen. No obstante, dicha lectura no se puede agotar en este esfuerzo, sino que debe ampliarse a partir de la recuperación de la intertextualidad que permite jugar con los múltiples discursos que atraviesan los documentos y confluyen en ellos aun cuando no se interrelacionen de manera necesariamente causal o coherente. En este sentido, a la par de los vínculos con otros textos que permiten convocar a una red de significados, red intertextual, debemos asumir, como sugiere Roland Barthes, que "hay que desconfiar de la naturalidad de las señalizaciones... reaccionar contra la impresión de evidencia... Frente a todo enunciado, por trivial y normal que parezca... hay que pensar siempre en lo que sucedería si el rasgo no estuviese marcado o si fuera indiferente... tener una especie de imaginación del contratexto...." 
En este análisis también resulta relevante intentar construir algunas hipótesis sobre la producción/recepción de las imágenes. Tarea compleja si se tiene en cuenta que, como anticipamos antes, desde el desciframiento histórico sólo es posible referir algunas reacciones colectivas, algunos discursos y actores: los más representativos, las más difundidas porque alcanzaron un lugar en la prensa, las que merecieron una respuesta desde el poder, las que en algún momento aparecieron en las calles, en las movilizaciones populares o dieron lugar a un eco lo suficientemente profundo y lo suficientemente amplio como para dejar algunas huellas en la memoria colectiva. En los hechos, resulta siempre más complejo intentar aprehender los discretos matices y las íntimas reacciones del espectador silencioso y hasta cierto punto "invisible" que, sin embargo, ha puesto en juego, en un cuerpo a cuerpo con la imagen, sus deseos, su erotismo y sus necesidades.

En este orden de ideas, tal como afirma Pavis, "conviene imaginar un modelo que combine una estética de la producción y de la recepción, que estudie su tensión dialéctica y que tenga en cuenta la recepción anticipada por la producción y la producción ligada a la actividad del espectador durante la recepción".5

No se trata de reiniciar la vieja discusión sobre el lugar de la objetividad/subjetividad, cosificando la imagen y limitando al productor/espectador al simple papel de la interpretación subjetiva. Pues, como ya se ha afirmado, dichas particiones resultan demasiado elementales y demasiado arcaicas como para traerlas nuevamente a la mesa de los debates. Antes bien, lo que conviene es situarnos en escenarios en donde la búsqueda de sentido nos lleve a la comprensión del juego de espejos que implica la compleja relación con la alteridad y con el "yo mismo/a" como condensaciones de significado en un mundo cambiante e interconectado que, sin embargo, nos confronta con el riesgo permanente de la "invisibilidad" y la enajenación.

Aprehender al "yo" en el "otro" en una imagen, conlleva el reconocimiento de identidades y de significados en permanente construcción, así como una reflexión profunda que nos permite indagar sobre la representación colectiva de los universos simbólicos con los que interactuamos permanentemente.

Esta intervención comprensiva que implica un ejercicio semiótico nos permite interpretar "no solamente los objetos producidos por el ser humano sino también las relaciones entre ellos y lo que éstas significan para él o para quienes los observan. El cálculo riguroso del accionar humano y de las relaciones que ahí se establecen, según un determinado contexto, nos conduciría al planteamiento de... esquemas de representación de lo vivido en cuanto efectos de sentido".

Aquí aparece la cuestión de la figura como "representación" del mundo realmente existente, del mundo de los objetos, al que no podemos acceder directamente (a menos que renunciemos a la razón, según Lacan), sino a través de mediaciones simbólicas histórica y socialmente construidas, que nos permiten "reconocer" la realidad e intervenir en ella. Siguiendo a Greimas: "El concepto de reconocimiento surge del problema más 
general de la legibilidad del mundo llamado natural. ¿Qué es lo naturalmente dado, qué es aquello inmediatamente legible para nosotros en el espectáculo del mundo? Suponiendo que se trate de las figuras, esas figuras sólo pueden ser concebidas como objetos si el rasgo semántico objeto se integra a la figura para convertirla en tal... sus significaciones forman parte de una lectura humana del mundo y no del mundo mismo.

Esa rejilla de lectura es la que nos vuelve el mundo significante permitiéndonos identificar las figuras como objetos, relacionarlos entre ellos, interpretar los movimientos como procesos, atribuibles o no a los sujetos, etc. De naturaleza semántica -y no visual, auditiva u olfativa-, funciona como código de reconocimiento que vuelve el mundo inteligible y maniobrable. Se comprende ahora que es la proyección de esta rejilla de lectura -especie de significado del mundo- sobre un lienzo pintado, grabado o fotografiado, la que permite reconocer el espectáculo que se supone debe representar".7

Así, productor/receptor se constituyen en constructores de sentido, de tal manera que los significados contenidos en toda expresión icónica los convocan como participantes de una rejilla de lectura común del mundo en la que aparecen asociados en una interacción simbólica permanente que los vincula, en un movimiento continuo, con las imágenes definidas como artefactos planarios.

En este punto se plantea un nuevo problema, el de la historicidad de la imagen y el relativismo cultural a la que es sometida su interpretación, variable en el tiempo y el espacio. Sin duda alguna, los efectos y las reacciones vividos ante ciertos espectáculos; el vigor de las respuestas sociales ante ciertas metáforas; el poder de algunos imaginarios sobre algunos colectivos humanos, tienen que ver con el momento histórico en el que se producen y se hacen circular. Situadas en otros tiempos y espacios, esas mismas figuras impactarán de manera distinta. Ello no descarta la hipótesis central de Greimas, cuando afirma: "La cuestión de la figuratividad de los objetos planarios (imágenes, cuadros, etcétera) se plantea sólo si una rejilla de lectura iconizante es postulada y aplicada a la interpretación de tales objetos, lo cual... no excluye la existencia de otros modos de lectura también legítimos... Una lectura iconizante es, sin embargo, una semiosis, es decir, una operación que conjuntando un significante y un significado tiene por efecto producir signos. La rejilla de lectura de naturaleza semántica requiere del significante planario, y al hacerse cargo de los paquetes de rasgos visuales, de densidad variable, que constituye en formantes figurativos, los dota de significados, transformando así las figuras visuales en signos-objeto".

La figuratividad-comprendida como una lectura/producción de las figuras planarias, es decir, de los iconos contenidos en una superficie plana, bidimensional- tiene por efecto la producción de la semiosis y nos coloca frente a una semiótica que podríamos designar como figurativa pues responde a ciertas pautas, códigos y signos propios y relativamente autónomos que la separan de la lectura de otros tipos de lenguajes, aunque su dominio no esté plenamente acotado. Ello porque "la figuratividad y las 
interrogaciones que la acompañan parecen rebasar los límites que el soporte planario, lugar de su manifestación, quiere asignarles: teniendo en cuenta el hecho de que las cualidades del mundo natural seleccionadas sirven para la construcción del significante de los objetos planarios... y también porque observamos que los discursos verbales portan en sí mismos su propia dimensión figurativa... los problemas planteados por el análisis de los textos visuales son comparables a los de los textos verbales... al presentar la iconización como el procedimiento de persuasión veridictoria no estamos tan alejados de la retórica de la imagen sugerida por Roland Barthes".

En este sentido, asumimos que ninguna semiótica de este tipo es ingenua o espontánea, sino que se ha construido histórica, social y culturalmente a partir de ciertos referentes que no sólo sugieren los énfasis, los borramientos, los significados de los que se apropia, sino que marcan la mirada diluyendo el supuesto de la existencia de una intuición pura, de una interpretación neutra o universal.

Lo que sugerimos es que estos horizontes interpretativos están ahí y juegan un papel, por lo que sería mejor explicitarlos, volverlos concientes y emplearlos racionalmente antes de iniciar una gestión exploratoria de las imágenes.

A partir de las hipótesis señaladas arriba, es posible intentar la construcción de "rejillas de lectura" que, a la vez que dan cuenta de la diversidad, permiten abrir la mirada para incluir en ella categorías que tienen que ver con el género, la cultura, la historia, la etnia o el poder. Por esta razón, como afirma Barthes, lo que probablemente hallaremos es "el lugar posible de los sentidos, o también la pluralidad de sentidos o el sentido como pluralidad. Cuando se dice que el análisis busca o define el sentido como una posibilidad, no se trata de una opción de tipo liberal... no se trata de determinar liberalmente las condiciones de posibilidad de la verdad, no se trata de un agnosticismo filológico... la posibilidad del sentido no es algo previo, indulgente y liberal... es el ser de lo plural...."10

Esta mirada recupera la otredad como condición para la existencia del "sí mismo", vuelve visible lo que hasta hoy ha permanecido oculto y genera alternativas que discuten cara a cara con afirmaciones que han sido dominantes. También absuelve a la ciencia de la solemnidad que la sujeta y obstruye, dotándola del recurso liberador de la risa y el juego.

Como sostiene Pavis: "La cuestión principal consiste en saber si podemos apreciar y analizar un espectáculo que nos es extraño, ya sea por su origen geográfico, cultural (o contexto sociohistórico, agregaríamos)... Por otra parte, los distintos grados de alejamiento... no son necesariamente un obstáculo para nuestra apreciación... La extrañeza es una de las formas de la alteridad... pero la alteridad no es un alejamiento del otro fatalmente irreductible. Ello no significa, sin embargo, negar su existencia ni la necesidad de tenerla en cuenta de una manera diferenciada... haciendo justicia al objeto descrito y enriqueciendo nuestra visión".11

En este sentido, coincidimos con César González cuando afirma: “La noción de un 
punto de vista fijo y de ángulo de observación predeterminado empieza a perder fuerza; empieza a cuestionarse la invariabilidad del punto de vista y se descubre la posibilidad de multiplicar las voces... (las miradas, las lecturas) lo mismo que la imposibilidad de unificarlas, ya que el problema no reside en lo observado, sino en el cómo y desde dónde se observa..."12

Así, el panóptico que dominó las prisiones en el Siglo XIX o el vigilante electrónico de las modernas cárceles de "máxima seguridad" pueden comprenderse como ficciones/ representaciones de la mirada única y universal hoy puesta en entredicho, refutada desde estas nuevas visiones que, lejos de sostener la unicidad de las perspectivas, nos permiten dar cuenta de la multiplicidad y de la particularidad como contenidos de un conjunto polisémico, no necesariamente homogéneo, que requiere de ser aprehendido en su riqueza, fragilidad y diversidad.

"La sucesiva autonomía de las partes no permite fijar una perspectiva central. En el seno de una representación, evitaremos homogeneizar, unificar o conciliar las distintas perspectivas. Nos encontramos en un poliperspectivismo comparable a la Vista de Toledo, el cuadro de El Greco, ilustración de un espacio global que reagrupa espacios y perspectivas específicas, unas junto a otras, en un mismo cuadro... no organizadas en torno a un punto de fuga.....13

Vista así, la representación (escénica o figurativa) deja de ser comprendida como unidad homogénea, y ante el analista surgen casi tangibles las densidades y tensiones variables que recorren sus elementos, así como sus interacciones e intercambios. "En lo que se refiere al espacio, no todos los elementos tienen la misma pertinencia. Hay zonas densas, en las que el mínimo detalle cobra importancia y zonas neutras de las que no parece que emerja sentido ni energía algunos. En cuanto a... los momentos clave en los que los conflictos se enlazan y desenlazan, les siguen a tiempos muertos. En cuanto al actor, las zonas de su cuerpo son más o menos significantes, o bien sus características hacen de él un personaje más o menos definido o individualizado."14

Por ello, para"leer" estas imágenes, estas representaciones espectaculares, es necesario recurrir a una mirada que cambie constantemente, a mecanismos de análisis "mutables" que den cuenta de los diversos relatos y sus matices contenidos en objetos hasta cierto punto inasibles que mueven a la comprensión y al azoro, al asombro y a la duda. "El espectáculo es un collage, y a veces incluso un conjunto de imágenes surrealistas, donde la fuerza de la imagen depende de la incongruencia de sus componentes."15

El cuerpo a cuerpo con la imagen: los iconos y su desciframiento

Desde una perspectiva meramente histórica, la conservación, almacenamiento y preservación de documentos, registros y huellas del pasado/presente, se asocian con la búsqueda de sentido que, a partir de su desciframiento, los/as historiadores/as creen posible. 
Ajena a una postura monotemática y autoinspirada, la historiografía contemporánea no duda en diversificar sus fuentes así como en asumir una mirada transdisciplinaria que permita la inclusión de múltiples horizontes de lectura, la exploración de las extensas zonas de oscuridad y de silencio que hoy son abiertas, expuestas y confrontadas, así como las lógicas, los personajes y las voces por tanto tiempo negadas o descartadas por las ciencias clásicas y el pensamiento único. Aparecen así tópicos, actores, discursos y escenarios que, como grandes metáforas del pasado -al que muchos desean muerto y sepultado-, nos hablan de la vitalidad de la historia, de su permanente actualización y nos confirman que esos registros, que se presumieron ajenos y lejanos, no son más que anotaciones autobiográficas, resúmenes irónicos del yo, que son, que han sido temidos, añorados... deseados.

Ver al otro, verse en el otro, son actos simultáneos y mutuamente incluyentes. Siendo así, la historia es el complejo e inagotable vínculo entre pasado y el presente. Tiempos en movimiento cuya densidad no puede ya medirse en un simple recuento cronológico. Espacios en permanente transformación intervenidos por profundos contactos que trasmutan los territorios en paisajes simbólicos, en anclas para la memoria, en textos y pretextos para el recuerdo y el olvido. Monumentos que condensan cargas figurativas vueltas relatos e imágenes que no necesariamente encuentran traducción a través de la palabra. Y el historiador, la historiadora, cazadores/as expectantes dispuestos/as a seguir "el rastro, la trayectoria, la energía de un desplazamiento, de una mirada, de un registro, a fin de capturar, así sea por instantes, de manera inconclusa, esa "lógica de sentido que mueve al texto y conmueve al espectador".16

Pero, ¿cómo encontrar los ejes que nos permitan "tejer"esa compleja red sociosemiológica que dé cuenta del texto/representación así como de la naturaleza y extensión de los contextos históricos, sociales, políticos y/o culturales implicados en él?; ¿cómo capturar los detalles, las densidades, las especificidades del relato sin perder de vista lo global, sus sentidos gruesos, el conjunto?; ¿cómo comprender los vínculos sin caer en una causalidad simplista, en un fatalismo dogmático o en la ingenua creencia en la casualidad?; ¿cómo aprehender el movimiento en la bidimensionalidad aparentemente "petrificada" del icono?; ¿cómo descifrar una metáfora sin reducirla a una traducción meramente lingüística? En fin, ¿cómo dejarnos seducir por una imagen identificándonos en ella sin perdernos del todo en el laberinto de la sinrazón?

Siguiendo a Pavis, reconocemos que los anteriores interrogantes "están sujetos al deseo (que busca y no encuentra), un deseo inagotable y siempre insatisfecho, que localiza en la visión de una red abierta -pero coherente- una posible ventana desde donde mirar y aprehender la armazón de una vectorización que da cuenta del movimiento, de la pluralidad, del equilibrio inestable y cambiante, de las lecturas posibles que dan sentido a un texto y a los iconos como narraciones vivas."17 
Niveles y recorridos de legibilidad: planos de análisis y funciones significativas

A partir de estos supuestos sugerimos algunos planos de análisis, que desde luego no son los únicos ni los últimos, para iniciar una lectura de las imágenes (en nuestro caso fotografías históricas, grabados y dibujos), textos y contextos en un recorrido de legibilidad.

Mediante la superposición y vectorización de planos significativos, ubicamos distintos niveles y funciones de sentido. En primer lugar, salta a la vista, en el plano de lo obvio, en el nivel de lo "evidente", la función referencial que se cumple a partir de la asociación, aparentemente lineal, del texto con la realidad; del objeto con las intencionali-dades que lo marcan. Es el caso de las fotografías signalíticas, mandadas a hacer para cumplir un trámite, completar un expediente, para dar testimonio de lo que se es y para representar fielmente al sujeto que se fotografía. Estos "retratos" responden a convenciones sociales y lo que aparece en ellas es lo social y culturalmente esperado.

Los objetos y los actores aprehendidos a través de esta función nos permiten reconstruir el relato que se muestra a nuestros ojos a partir de signos e indicios evidentes que, no obstante su intencionalidad, no pueden escapar del todo a la ambigüedad de su desciframiento, ya que estos signos que pretenden ser "la realidad misma" pueden tener la función de suplantación más que de fiel reproducción.

Para ir más allá de este primer plano, es necesario examinar "el nivel profundo de organización narrativa de la representación, su fábula, el esquema fundamental de la narración, la lógica de las acciones y la sintaxis de los personajes".18

La fábula proporciona algunas claves que nos permiten situar al icono en un contexto sociocultural e histórico, pues éste se construye a partir de una serie de elecciones ancladas en un espacio-tiempo que le da sentido. Son elementos constitutivos de la fábula: el sujeto que actúa, una intención actancial ${ }^{19}$ que en este nivel se esboza apenas, el mundo posible en donde tiene lugar, el movimiento, su causa y su propósito último.

Paralela y simultáneamente, proponemos incluir una enunciación de la intertextualidad/subtextualidad que atraviesa a dichos iconos, para situar dentro de la misma "rejilla de significación" los libros de texto y sus lecciones, los discursos oficiales sobre educación y los debates que produjeron, las movilizaciones y sus actores.

Un nivel aún más profundo es el actancial, referido al studium, en donde entra en juego el creador que construye el trasfondo de la representación, organiza los indicios y da lugar a una acción general que involucra a los actores y sus movimientos, pero también el objetivo de la lente que incluye a los objetos, actores y otros contenidos como la luz y el espacio.

Sin duda, en el caso de las fotografías, en este nivel importa el acuerdo previo entre el creador y los actores que son retratados. Sin embargo, aun cuando dicho acuerdo se explicite y se cumpla, debemos reconocer la existencia de una relativa espontaneidad, de elementos que escapan al control del fotógrafo y rompen las denotaciones obvias permitiendo la irrupción de referentes simbólicos no previstos. En las fotografías ins- 
tantáneas, los convenios antecedentes son mínimos o no existen, lo que no implica que las intencionalidades subjetivas desaparezcan sino que adquieren otro peso y otros mecanismos de intervención.

Finalmente, mencionaremos la función subtextual que se vincula al puntum, centro de densidad de la imagen cuya producción/recepción se conecta con el inconsciente descentrando la mirada de la significatividad planaria y vinculándola con mundos interiores. El puntum no puede planearse, pues, al contrario de la fotografía de choque que se propone de antemano impactar al espectador, el puntum es un elemento no racional, un momento de suma intensidad dramática, que nos enfrenta cara a cara con la muerte, el amor o la locura, entre otros universos interiores inasibles a la razón.

El puntum no siempre está presente en una fotografía; cuando se encuentra puede tratarse de una mirada, un gesto, un rasgo, un objeto o de la relación de estos u otros elementos. Pero, más allá de su anclaje en la representación, el puntum refiere a un subtexto que produce una identificación del sentido inconsciente del texto. Constituiría, según Pavis, "una subpartitura corporal detrás de la partitura visible del actor".20

A través del puntum percibimos lo que está oculto o lo que no está. Nos encontramos con el significado latente de la puesta en escena, justo cuando la distinción entre significado y significante ya no es operatoria como en el plano manifiesto y, por lo tanto, paradójicamente, en este instante en que descendemos al nivel más profundo de la puesta en escena, nuestra comprensión se desdibuja en un juego de emociones apenas expresables. Los mensajes de anclaje situados en la materialidad de la fotografía pueden detener el disparo de la connotación y resituarnos en el mundo del sentido.

\section{Vectorización}

La vectorización implica la identificación de los núcleos de sentido que atraviesan los documentos que se analizan. Estos ejes de sentido indican no sólo los nudos narrativos más relevantes, desde el punto de vista de la lógica de los textos, sino sus puntos de partida y su direccionalidad, es decir, su movimiento interno.

Los vectores, como ya se ha mencionado, recorren todo el texto, pero su significación implica densidad, como en el caso de los vectores acumuladores, que se refieren a la repetición, la confirmación y la acumulación de indicios discriminatorios que ayudan a identificar ciertos rasgos de carácter de los actores, su pertenencia a determinados colectivos, el momento histórico que se retrata, etc., o los vectores conectores que nos permiten, a través de la aprehensión de las oposiciones más marcadas, de las distancias más claras, de las zonas de vacío o las tensiones reveladas, "el sistema de regularidades que producen el efecto de conexión o desconexión".21

En cambio, los vectores secantes se refieren a las rupturas o cambios bruscos que nos hacen abandonar un sistema de referencias y nos llevan a otro. Este vector puede darse si las conexiones de sentido nos llevan a un desplazamiento de sentido que genera un 
fuerte efecto de sorpresa o de extrañamiento. "La nueva identidad del objeto rompe el hilo conductor precedente y obliga a partir de nuevas bases. La acumulación y el desplazamiento desestabilizan la percepción",22 generando una ruptura y la articulación con un nuevo sistema referencial.

Finalmente, el vector de embrague implica la participación de un eje en el movimiento de otro. De esta manera, los vínculos significativos, sugieren el movimiento interno de la narración.

Esto tiene que ver con la transición de un universo ficcional a otro: por ejemplo, el recorrido siempre posible a través de distintas épocas. Pero también con la posibilidad de una mirada obtusa que nos permite ver diversos ángulos fuera o dentro de la superficie planaria. Como en Las Meninas de Velázquez, en donde el juego de espejos devuelve la mirada del espectador y del creador a través de la mujer que, sonriente, observa de reojo a esos personajes imaginarios que la "ven" desde fuera del cuadro.

Es en este punto donde la multiculturalidad y la hermenéutica analógica barroca ${ }^{23}$ nos vuelven comprensible lo aparentemente extraño o ajeno. Pues a través de la aceptación y reconocimiento de la diversidad, podemos "leer" históricamente producciones, contenidos e imágenes situadas en otros espacios y tiempos, aquellos que, vivos y actuantes, nos interpelan, convocan y nombran desde un pasado/presente que nos involucra y pertenece.

\section{Los indicios}

La lectura que hemos propuesto, hecha a partir de varios niveles de significatividad y de una vectorización de la narración o narraciones contenidas en una imagen, nos permite dar cuenta, como ya dijimos, de la representación como un todo, del carácter global de la historia que en ella se cuenta. Pero ello nos conduce, necesariamente, a la identificación de indicios ${ }^{24}$ que nos permiten construir enlaces, vincular significados e, incluso, ir más allá del texto icónico y de sus propios marcos.

Estos indicios situados en los detalles, pero también en los elementos singulares y específicos que confluyen en la trama y la constituyen, son huellas relevantes sin las cuales el sentido se fuga sin remedio. La elección de estos componentes escénicos identificables y significativos es histórica, viene de tradiciones heredadas que, no obstante este carácter, nos permiten aprehender los contornos y la organización interna de categorías de suyo inestables y fragmentarias que hacen posible una aproximación al sentido del texto espectacular.

\section{a. Actores, vestuario, maquillaje}

Actores, vestuario y maquillaje son elementos que, en una representación, resultan difíciles de separar. Podríamos afirmar que este trinomio construye al personaje y lo 
identifica, es decir, le otorga identidad. No es fácil definir dónde empieza el vestuario y separarlo de otros conjuntos como las insignias o los accesorios; además, cada elemento tiene sus funciones propias, su relevancia autónoma.

Posiblemente, lo primero que se muestra ante el espectador es el actor, su carácter, el plano que ocupa en la composición fotográfica, lo que hace o parece hacer, la emoción que pone en juego, son impresiones indiciales cuyo registro resulta imperativo. Sin duda, la recuperación del actor nos remite también a su cuerpo. La relación del cuerpo y su postura con el escenario; las partes del cuerpo y sus movimientos; la proximidad o alejamiento de los otros, de lo otro; las luces y las sombras que le ocultan o iluminan; los énfasis del rostro: el gesto, la mirada, la boca y las mejillas, "hablan" más allá del actor y a través de él.

En este movimiento dramático puesto en juego por el actor, el vestuario cumple un papel definitivo; no es un disfraz, una cubierta que se impone a su cuerpo y lo convierte en algo distinto. Por el contrario, "el vestuario invade naturalmente el cuerpo del actor... se integra al trinomio de la representación (espacio, tiempo y acción) haciendo que destaque su movimiento... El uso del vestuario se funda, más segura y concretamente que cualquier otro sistema significante de la representación, en observaciones comprobables y en redes de signos estrictamente codificadas.....25

Por esta razón, el vestuario es un embrague casi natural entre el cuerpo del actor y el personaje que representa, lo cual nos remite a una producción global de sentido en donde el género, el poder y la identidad toman su lugar.

El maquillaje que, según Pavis, "es el vestuario inscrito en la piel del actor, viste tanto el cuerpo como el alma de quien lo lleva"26 y tiene una importancia estratégica en el juego de seducción, ocultamiento o revelación que se filtran a través de esta delgada película.

El maquillaje modifica el cuerpo del actor y el imaginario que lleva aparejado. Cumple una función simbólica que va de otorgar verosimilitud a los personajes a suplantarlos. Sus efectos son múltiples pues, como parte constitutiva del relato, puede producir terror, seducción o risa pero nunca indiferencia. "El disfraz del cuerpo y del rostro duplica el vértigo y la ambigüedad de la identidad del espectador, ya se trate de disfrazar o de travestir el género, la edad o la naturaleza humana del actor.".7

\section{b. Objetos}

Los objetos que observamos en el escenario pueden definirse como todo lo que no es el actor. Por sus características propias y por el lugar y la función que ocupan en la representación, puede situárseles en un continuum que va de la materialidad a lo simbólico de acuerdo con su objetividad. De esta manera, en la escena podemos encontrar objetos naturales, formas que constituyen materialidades legibles, objetos nombrados o bien concebidos de manera abstracta. 
De acuerdo con lo anterior, consideraremos a los objetos como elementos constitutivos y constituyentes de la trama y no como simples decorados o accesorios puestos ahí casualmente para "rellenar" el escenario.

c. Escenario, planos, iluminación y otras marcas intencionadas:

la propiedad, el género, el poder

Al considerar estos elementos, no podemos dejar de aludir al ojo de la cámara lo mismo que al ojo de quien obtura el disparador y crea la imagen transformándola en una huella de larga duración. Por esta razón, desde esta lectura, importa el encuadre, la distancia, la escala de planos, los ajustes mediante el montaje, así como las asociaciones libres realizadas mediante el montaje en el interior del plano. El juego de luces y sombras que enfatizan, obscurecen o aclaran marcando los tonos, los énfasis y los borramientos que se emplean para proponer un mensaje y/o desplazar discursos. De estas situaciones, de estos juegos semánticos podemos desprender hipótesis que nos hablan desde la historia, la cultura y el inconsciente, sobre las relaciones de propiedad, género y poder puestas en juego en esos guiños simbólicos que las imágenes nos devuelven a quienes con asombro y curiosidad atisbamos para comprender, para comprendernos.

\section{Notas}

1 Pavis, Patrice (2000): El análisis de los espectáculos, Paidós, México, p. 33.

${ }^{2}$ Pavis, op. cit., pp. 32-33.

${ }^{3}$ Ver Rodríguez Villeneuve, citado por Pavis, Patrice, p. 55.

${ }^{4}$ Barthes Roland (1990): La aventura semiológica, Paidós, Buenos Aires. p. 291.

${ }^{5}$ Barthes, op. cit., p. 41.

${ }^{6}$ Hernández Aguilar, Gabriel (1995): Figuras y estrategias en torno a una semiótica de lo visual, UAP/Siglo XXI, México, p. 9.

${ }^{7}$ Algirdas J. Greimas (1995): “Semiótica figurativa y semiótica plástica”, en Hernández Aguilar, Gabriel: Figuras y estrategias en torno a una semiótica de lo visual, UAP/Siglo XXI, México, p. 23.

${ }^{8} \mathrm{lbid}, \mathrm{p} .24$.

${ }^{9} \mathrm{lbid}, \mathrm{pp} .25$ y 26.

${ }^{10}$ Barthes, Roland, op. cit., p. 291

${ }^{11}$ Pavis, op. cit., p. 272.

${ }^{12}$ González Ochoa César (1986): Imagen y sentido. Elementos para una semiótica de los mensajes visuales, UNAM, México, p. 13. 


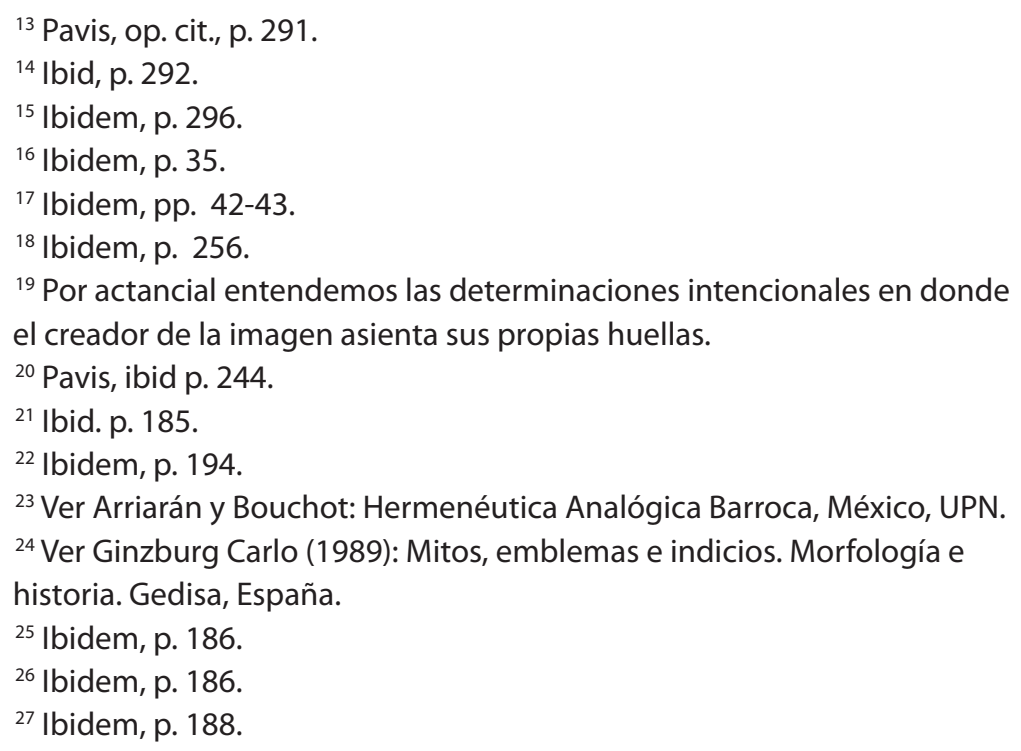

